\title{
Pulmonary atresia with ventricular septal defect and coronary artery fistula: a late presentation
}

\author{
W T VIGNESWARAN, * J C S POLLOCK† \\ From the Ibn Al Bitar Hospital, Baghdad, Iraq
}

SUMMARY A 41 year old man presented with cyanosis and progressive shortness of breath. Cardiac angiography showed absent central pulmonary arteries, ventricular septal defect, and a fistula between the left coronary artery and pulmonary artery. Most of the blood reaching the lungs came through this fistula. An attempt at surgical palliation was unsuccessful.

Obstruction of the right ventricle, right ventricular outflow tract, and pulmonary arteries was seen in about $25-30 \%$ of all congenital heart defects. ${ }^{1}$ There is a range of abnormalities in pulmonary atresia with ventricular septal defect-from valve atresia to absent central pulmonary arteries (truncus type IV). ${ }^{2}$ The course and presentation are varied and there are many surgical treatment options. These defects can present in the first few weeks of life as severe cyanosis and acidosis, as in those infants in whom the pulmonary flow is derived mainly through the ductus arteriosus, or in later life when patients outgrow their well developed aortopulmonary collaterals.

We report an unusual case of a man of 41 who, despite having no central pulmonary arteries, a ventricular septal defect, and a coronary arterypulmonary artery fistula, had minimal symptoms.

\section{Case report}

A 41 year old man was referred to the Ibn Al Bitar Hospital, Baghdad with a history of progressive shortness of breath on exertion. He also had a recent episode of haemoptysis. There was no history of chest pain. He was of average build (weight $57 \mathrm{~kg}$ ) and had central cyanosis and grade III clubbing. His pulse was 80 per minute with regular rhythm; his blood pressure was $120 / 80 \mathrm{~mm} \mathrm{Hg}$. There was a single second heart sound at the left sternal border with no murmurs. The haemoglobin concentration was $22 \mathrm{~g} / \mathrm{dl}$ with a haematocrit of $65 \%$. The electrocardiogram showed sinus rhythm with evidence of right axis deviation and right ventricular hypertro-

Requests for reprints to $\mathrm{Mr} \mathrm{W} \mathrm{T}$ Vigneswaran, FRCSEd, Department of Cardiac Surgery, Royal Infirmary, Lauriston Place, Edinburgh EH3 9YW.

Present addresses: *Royal Infirmary, Edinburgh; †Royal Infirmary, Glasgow. phy. The chest radiograph showed cardiomegaly with reticulation in both lung fields.

The patient underwent cardiac catheterisation and the measured oxygen saturations were as follows: superior vena cava $63 \%$, inferior vena cava $72 \%$, mid-right atrium $68 \%$, right ventricular apex $65 \%$, left ventricle $94 \%$, and ascending aorta $85 \%$. The pressure measurements were right ventricle 105/0-9 $\mathrm{mm} \mathrm{Hg}$, left ventricle $105 / 0-9 \mathrm{~mm} \mathrm{Hg}$, and ascending aorta $115 / 70 \mathrm{~mm} \mathrm{Hg}$. Angiography showed obstruction of the right ventricular outflow tract, no central pulmonary arteries, and a high ventricular septal defect. The aortic root injection showed a fistula between the coronary artery and pulmonary artery. Detailed coronary angiography showed a communication between the left circumflex coronary artery and the pulmonary arteries. Most of the blood reaching the lungs came through this fistula (figure).

With a view to disconnecting the fistula from the coronary circulation and constructing a modified Blalock-Taussig shunt, we performed an exploratory left anterolateral thoracotomy. At operation the fistula was isolated, but the distal main, left, and right pulmonary arteries were not found. Several small thin-walled communicating vessels were found at the hilum. Any attempt to find a larger vessel would have compromised these vessels and we had to abandon the procedure. The patient made a satisfactory recovery after the operation and was discharged home on the tenth postoperative day. He refused any further surgical treatment.

\section{Discussion}

The definitive repair for pulmonary atresia and ventricular septal defect is closure of the defect and construction of a right ventricular pulmonary artery continuity. ${ }^{3-5}$ This can be performed as the primary 



Fig Left coronary artery angiogram showing the fistula arising from the circumflex coronary artery and filling the pulmonary circulation. LM, left main coronary artery; $L A D$, left anterior descending artery.

procedure if the pulmonary artery is large enough or as a two stage procedure in which a systemic to pulmonary shunt is constructed to allow the pulmonary artery to grow. In patients with truncus type IV defect, the collateral vessels should be included in any attempt at correction.
The presence of a coronary artery-pulmonary artery fistula increases the risk of myocardial ischaemia. Life expectancy in these patients is further shortened by bacterial endocarditis, dissection embolisation and rupture of the fistula, or congestive cardiac failure and pulmonary hypertension. Early surgical intervention is recommended for this condition. ${ }^{6-9}$

In our patient there were no murmurs despite the coronary artery-pulmonary artery fistula. This was probably an indication of a considerable increase in pulmonary vascular resistance. Because of the features noted above and the longstanding cardiac defect in our patient, we planned only to disconnect the fistula from the coronary circulation and to reconstruct a pulmonary systemic shunt. The absence of a sizeable distal pulmonary artery, however, precluded any shunting. In the presence of adequate resources, he might be a candidate for cardiopulmonary transplantation. Nevertheless, he has survived 41 years with minimal symptoms while receiving pulmonary blood through the coronary artery fistula.

\section{References}

1 Emmanouilides GC. Obstructive lesion of the right ventricle and pulmonary arterial tree. In: Moss AJ, Adams FH, Emamanouildes GC, eds. Heart disease in infants, children and adolescents. Baltimore: Williams and Wilkins, 1977:226-57.

2 Sotomara RF, Edwards JE. Anatomic identification of so called absent pulmonary artery. Circulation 1978;57:624-33.

3 Rastelli RF, Ongley PA, Davis GD, Kirklin JW. Surgical repair for pulmonary valve atresia with coronary pulmonary artery fistula: report of a case. Mayo Clin Proc 1965;40:521-7.

4 Piehler JM, Danielson GK, McGoon DC, Wallace RB, Fulton RE, Mair DD. Management of pulmonary atresia with ventricular septal defect and hypoplastic pulmonary arteries by right ventricular outflow construction. J Thorac Cardiovasc Surg 1980;80:552-67.

5 Matsuda $\mathrm{H}$, Hirose $\mathrm{H}$, Nakano $\mathrm{S}$, et al. Management of large aortopulmonary collateral arteries in patients with ventricular septal defect and pulmonary atresia: simultaneous ligation through median sternotomy during intracardiac repair. Ann Thorac Surg 1985;40:593-8.

6 Liberthson RR, Sagar K, Berkoben JP, Weintraub RM, Levine FH. Congenital coronary arteriovenous fistula. Circulation 1979;59:849-54.

7 Lowe JE, Newland Oldham H Jr, Sabiston DC. Surgical management of congenital coronary artery fistula. Ann Surg 1981;194:373-80.

8 Daizzi RP, Caprioli G, Aiazzi L, et al. Distribution and anomalies of coronary arteries in tetralogy of Fallot. Circulation 1980;61:95-102.

9 Ongley PA, Rahimtoola SH, Kincaid OW, Kirklin JW. Continuous murmurs in tetralogy of Fallot and pulmonary atresia with ventricular septal defect. $\mathrm{Am}$ J Cardiol 1966;18:821-6. 